\title{
Treatment of Patients with the Hypereosinophilic Syndrome with Mepolizumab
}

\section{Citation}

Rothenberg, Marc E., Amy D. Klion, Florence E. Roufosse, Jean Emmanuel Kahn, Peter F. Weller, Hans-Uwe Simon, Lawrence B. Schwartz, et al. 2008. "Treatment of Patients with the Hypereosinophilic Syndrome with Mepolizumab." New England Journal of Medicine 358 (12) (March 20): 1215-1228. doi:10.1056/nejmoa070812.

\section{Published Version}

doi:10.1056/NEJMoa070812

\section{Permanent link}

http://nrs.harvard.edu/urn-3:HUL.InstRepos:28702415

\section{Terms of Use}

This article was downloaded from Harvard University's DASH repository, and is made available under the terms and conditions applicable to Other Posted Material, as set forth at http:// nrs.harvard.edu/urn-3:HUL.InstRepos:dash.current.terms-of-use\#LAA

\section{Share Your Story}

The Harvard community has made this article openly available.

Please share how this access benefits you. Submit a story.

\section{Accessibility}




\title{
The NEW ENGLAND \\ JOURNAL of MEDICINE
}

ESTABLISHED IN 1812

MARCH 20, 2008

VOL. 358 NO. 12

\section{Treatment of Patients with the Hypereosinophilic Syndrome with Mepolizumab}

\author{
Marc E. Rothenberg, M.D., Ph.D., Amy D. Klion, M.D., Florence E. Roufosse, M.D., Ph.D., \\ Jean Emmanuel Kahn, M.D., Peter F. Weller, M.D., Hans-Uwe Simon, M.D., Ph.D., \\ Lawrence B. Schwartz, M.D., Ph.D., Lanny J. Rosenwasser, M.D., Johannes Ring, M.D., Ph.D., \\ Elaine F. Griffin, D.Phil., Ann E. Haig, B.S.N., Paul I.H. Frewer, M.Sc., Jacqueline M. Parkin, M.B., B.S., Ph.D., \\ and Gerald J. Gleich, M.D., for the Mepolizumab HES Study Group*
}

\section{BACKGROUN D}

The hypereosinophilic syndrome is a group of diseases characterized by persistent blood eosinophilia, defined as more than 1500 cells per microliter with end-organ involvement and no recognized secondary cause. Although most patients have a response to corticosteroids, side effects are common and can lead to considerable morbidity.

\section{METHODS}

We conducted an international, randomized, double-blind, placebo-controlled trial evaluating the safety and efficacy of an anti-interleukin- 5 monoclonal antibody, mepolizumab, in patients with the hypereosinophilic syndrome. Patients were negative for the FIP1L1-PDGFRA fusion gene and required prednisone monotherapy, 20 to $60 \mathrm{mg}$ per day, to maintain a stable clinical status and a blood eosinophil count of less than 1000 per microliter. Patients received either intravenous mepolizumab or placebo while the prednisone dose was tapered. The primary end point was the reduction of the prednisone dose to $10 \mathrm{mg}$ or less per day for 8 or more consecutive weeks.

\section{RESULTS}

The primary end point was reached in $84 \%$ of patients in the mepolizumab group, as compared with $43 \%$ of patients in the placebo group (hazard ratio, 2.90 ; $95 \%$ confidence interval [CI], 1.59 to 5.26 ; $\mathrm{P}<0.001$ ) with no increase in clinical activity of the hypereosinophilic syndrome. A blood eosinophil count of less than 600 per microliter for 8 or more consecutive weeks was achieved in $95 \%$ of patients receiving mepolizumab, as compared with $45 \%$ of patients receiving placebo (hazard ratio, 3.53; 95\% CI, 1.94 to 6.45; $\mathrm{P}<0.001)$. Serious adverse events occurred in seven patients receiving mepolizumab (14 events, including one death; mean $[ \pm S D]$ duration of exposure, $6.7 \pm 1.9$ months) and in five patients receiving placebo (7 events; mean duration of exposure, $4.3 \pm 2.6$ months).

\section{CONCLUSIONS}

Our study shows that treatment with mepolizumab, an agent designed to target eosinophils, can result in corticosteroid-sparing for patients negative for FIP1L1PDGFRA who have the hypereosinophilic syndrome. (ClinicalTrials.gov number, NCT00086658.)
From the Cincinnati Children's Hospital Medical Center, University of Cincinnati, Cincinnati (M.E.R.); the National Institute of Allergy and Infectious Diseases, Bethesda, MD (A.D.K.); Service de Médecine Interne, Hôpital Erasme, Université Libre de Bruxelles, and the Institute for Medical Immunology, Gosselies, Belgium (F.E.R.); Service de Médecine Interne, Hôpital Foch, Suresnes, France (J.E.K.); Beth Israel Deaconess Medical Center, Harvard Medical School, Boston (P.F.W.); the University of Bern, Bern, Switzerland (H.-U.S.); Virginia Commonwealth University, Richmond (L.B.S.); Children's Mercy Hospital, Kansas City, MO (L.J.R.); Technische Universität München, Munich, Germany (J.R.); Envision Pharma, Horsham, United Kingdom (E.F.G.); GlaxoSmithKline, King of Prussia, PA (A.E.H.); GlaxoSmithKline, Middlesex, United Kingdom (P.I.H.F., J.M.P.); and University of Utah School of Medicine, Salt Lake City (G.J.G.). Address reprint requests to Dr. Rothenberg at the Division of Allergy and Immunology, Department of Pediatrics, Cincinnati Children's Hospital and Medical Center, 3333 Burnet Ave., Cincinnati, $\mathrm{OH}$ 45229 , or at rothenberg@cchmc.org.

*Members of the Mepolizumab Hypereosinophilic Syndrome (HES) Study Group are listed in the Appendix.

N Engl J Med 2008;358:1215-28 Copyright @) 2008 Massachusetts Medical Society. 
T HE HYPEREOSINOPHILIC SYNDROME consists of several heterogeneous disorders characterized by sustained blood eosinophilia and eosinophil-related end-organ damage, with no identifiable cause, such as parasitic infection. ${ }^{1}$ The objective of treatment is long-term reduction of blood and tissue eosinophil levels to prevent end-organ damage and thromboembolic events. Except for the myeloproliferative variant of the hypereosinophilic syndrome (associated with the Fip1-like 1-platelet-derived growth factor receptor $\alpha$ fusion gene [FIP1L1-PDGFRA]), for which imatinib mesylate is considered first-line therapy, current management is based on long-term systemic corticosteroids. ${ }^{1-4}$

Eosinophil development from hematopoietic progenitors is regulated mainly by interleukin $-5,5$ which has a selective role in eosinophil maturation, differentiation, mobilization, activation, and survival. ${ }^{5-11}$ Since interleukin-5 appears to contribute to the pathogenesis of some phenotypes of the hypereosinophilic syndrome, ${ }^{12}$ interleukin-5 inhibition is a logical therapeutic target for this disease.

Mepolizumab is a fully humanized, anti-interleukin-5 monoclonal immunoglobulin G1 antibody with a half-life of approximately 19 days; it does not fix complement. ${ }^{13,14}$ By binding to free interleukin-5 with high affinity and specificity, it prevents interleukin-5 from associating with the interleukin-5 receptor $\alpha$ chain on the surface of eosinophils and their progenitors. In preliminary studies of healthy volunteers and patients with atopy, mepolizumab had few side effects and lowered blood eosinophil levels. ${ }^{15-19}$ Subsequent studies suggested that mepolizumab may have clinical value in patients with the hypereosinophilic syndrome. ${ }^{20-22}$

After these initial reports, we conducted a randomized, double-blind, placebo-controlled trial of targeted therapy for patients with the hypereosinophilic syndrome. Our aim was to evaluate the effects of mepolizumab on corticosteroid sparing and the maintenance of clinical stability in patients with disease that requires control with the use of corticosteroids.

\section{METHODS}

\section{STUDY POPULATION}

The study patients were 18 to 85 years of age and had the hypereosinophilic syndrome (defined as a blood eosinophil count $>1500$ per microliter for $\geq 6$ months and eosinophilia-related organ involvement or dysfunction, with no identifiable secondary cause of eosinophilia' ${ }^{23}$ ). All patients were negative for the FIP1L1-PDGFRA fusion gene, on the basis of in situ hybridization to detect deletion of the cysteine-rich hydrophobic domain 2 (CHIC2) locus, a FIP1L1-PDGFRA surrogate, in peripheralblood mononuclear cells. ${ }^{24}$

\section{STUDY DESIGN}

Our randomized, double-blind, placebo-controlled, parallel-group, multicenter study, involved 26 sites in the United States, Canada, Belgium, France, Germany, Italy, Switzerland, and Australia. It was conducted from March 2004 through March 2006. After screening, patients entered a run-in period of up to 6 weeks, during which noncorticosteroid medications for the hypereosinophilic syndrome were discontinued and prednisone monotherapy (20 to $60 \mathrm{mg}$ per day for at least 1 week) was administered to achieve a stable clinical status (defined as no new or worsening clinical signs or symptoms of the hypereosinophilic syndrome and a blood eosinophil count of $<1000$ per microliter). Methylprednisolone, prednisolone, or triamcinolone could be used at a dose equivalent to that of prednisone, at the investigator's discretion. (See Supplementary Appendix 1, available with the full text of this article at www.nejm.org, for details on blinding, exclusion criteria, eosinophil-derived neurotoxin enzyme-linked immunosorbent assay methods, and corticosteroid conversion.)

Patients whose clinical symptoms were stabilized with the use of prednisone monotherapy (20 to $60 \mathrm{mg}$ per day) or the equivalent were randomly assigned in a one-to-one ratio to receive intravenous infusions of either mepolizumab (750 mg) or placebo (saline) and were stratified according to the daily prednisone dose $(\leq 30 \mathrm{mg}$ or $>30 \mathrm{mg}$ ) at baseline. Mepolizumab or placebo was administered every 4 weeks during a 36-week period (final infusion at week 32). The prednisone dose was tapered, starting at week 1, using a predefined algorithm based on eosinophil counts and clinical manifestations of the hypereosinophilic syndrome (Fig. 1A). Week 32 was the last visit at which a taper dose could be prescribed; the patient then took that dose until week 36, the end of the treatment period. This approach to corticosteroid dosing was used to maintain control by allowing for corticosteroid rescue therapy for disease flares.

Patients who completed the trial or withdrew 


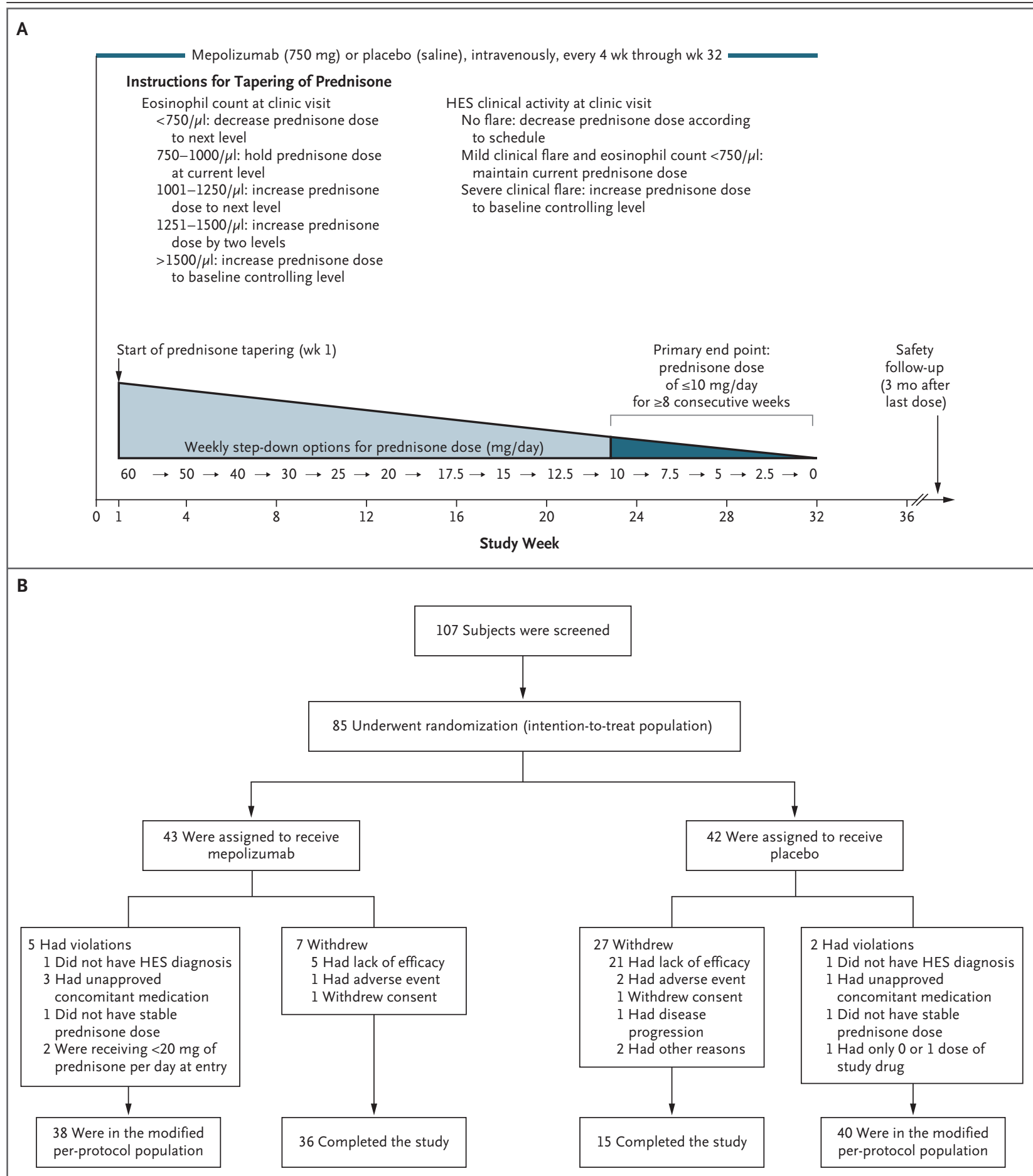

Figure 1. Study Design and Enrollment and Follow-up of Patients.

Panel A illustrates the study design and the prednisone tapering algorithm. The dose of prednisone (or equivalent) was adjusted at weekly clinic visits according to the blood eosinophil count and the clinical activity of the hypereosinophilic syndrome (HES). At the discretion of the investigator, tapering below $20 \mathrm{mg}$ per day could have been achieved through alternate-day dosing, and tapering below $10 \mathrm{mg}$ per day could have been more gradual, with a decrease in dose of less than $2.5 \mathrm{mg}$ per day per week. Panel B shows the screening, enrollment, random assignment, and follow-up of patients. Patients could have had more than one type of protocol violation.

The New England Journal of Medicine

Downloaded from nejm.org on May 1, 2016. For personal use only. No other uses without permission.

Copyright @ 2008 Massachusetts Medical Society. All rights reserved. 
early but received at least two doses of the study drug entered an open-label extension study evaluating the long-term safety, efficacy, and optimal dosing frequency of intravenous mepolizumab. Patients choosing not to continue in the extension study completed a safety follow-up visit 3 months after their last dose of study medication.

\section{CLINICAL EFFICACY}

The primary end point was the reduction of the prednisone dose to $10 \mathrm{mg}$ or less per day (or the equivalent) for 8 or more consecutive weeks. A prednisone dose of $10 \mathrm{mg}$ or less per day was considered clinically meaningful and a response lasting 8 weeks was considered durable. All end points were analyzed with the use of data from the intention-to-treat population (85 patients who provided written informed consent, were randomly assigned to a study drug, and received at least one dose). The primary end point data were confirmed in a modified per-protocol population (78 patients). Protocol violations (by two patients in the placebo group and five in the mepolizumab group) included a lack of documented history of the hypereosinophilic syndrome, use of unapproved concomitant medications, inability to stabilize the prednisone dose within the specified range during screening, and a prednisone dose of less than $20 \mathrm{mg}$ per day at study entry. Data from the patients who violated the protocol were included in the intention-to-treat analysis.

Secondary end points were a blood eosinophil count of less than 600 per microliter for 8 or more consecutive weeks, the time to treatment failure (defined as clinical worsening requiring other therapy for the hypereosinophilic syndrome, a prednisone dose of $>60 \mathrm{mg}$ per day, or withdrawal from the study for any reason), a prednisone dose of $7.5 \mathrm{mg}$ or less per day, receipt of no prednisone for 1 day or more, the mean daily prednisone dose at week 36, and a prednisone dose of $10 \mathrm{mg}$ or less per day by week 20 and for 8 or more consecutive weeks. Post hoc exploratory end points included a prednisone dose of $10 \mathrm{mg}$ or less per day for 24 or more weeks and the receipt of no prednisone during the treatment period, maintained until study completion.

We assessed the effects of the study drug on physical or psychological symptoms of the hypereosinophilic syndrome, health status, and limitations of daily living, using the Medical Outcomes Study 12-item Short Form General Health Survey
(SF-12) (version 2) physical and mental component summary scores and the Rotterdam Symptom Checklist.

\section{SAFETY}

Safety was assessed with the use of adverse event reports, laboratory tests (clinical chemical and hematologic tests and urinalysis), electrocardiograms, physical examinations, and vital signs recorded both before and after infusion.

\section{STATISTICAL ANALYSIS}

We calculated that 84 patients who could be evaluated (42 per study group) would be required to provide a statistical power of $90 \%$, at a two-sided significance level of $5 \%$, to detect a difference of $33 \%$ between the two study groups in the percentage of patients in whom in the primary end point was reached (assuming the percentage of patients with a prednisone dose of $\leq 10 \mathrm{mg}$ per day for $\geq 8$ weeks was $80 \%$ in the mepolizumab group and $47 \%$ in the placebo group). Differences in the incidences of the primary end point were tested using a Cochran-Mantel-Haenszel test, with stratification according to the prednisone (or the equivalent) dose ( $\leq 30 \mathrm{mg}$ or $>30 \mathrm{mg}$ ) at baseline, at a $5 \%$ two-sided significance level in the intentionto-treat population. In the primary prespecified analysis, odds ratios were also calculated. Relative risks (without stratification on the basis of prednisone dose at baseline) and hazard ratios (with stratification) were also calculated in post-hoc analyses. The proportional-hazards assumption was assessed by inspection of the log-log survival curves.

Adverse events were also summarized. A logrank test was used to compare the time to an adverse event between the two study groups, including data from patients who withdrew from the study.

An investigator advisory board, including the authors and the sponsor, designed the study, with scientific guidance from the Food and Drug Administration and the European Committee for Proprietary Medicinal Products. The sponsor was responsible for data collection and quality control and held the data but made them available, after ensuring confidentiality, to all the authors. All the authors analyzed and interpreted the data, wrote the manuscript, made the decision to publish, and vouch for the completeness and accuracy of the data. 


\begin{tabular}{|c|c|c|c|c|}
\hline Characteristic & $\begin{array}{l}\text { Mepolizumab } \\
\quad(\mathrm{N}=43)\end{array}$ & $\begin{array}{l}\text { Placebo } \\
(\mathrm{N}=42)\end{array}$ & $\begin{array}{c}\text { All } \\
(N=85)\end{array}$ & P Value \\
\hline Age $-y r$ & $47.0 \pm 16.2$ & $49.1 \pm 14.4$ & $48.1 \pm 15.3$ & 0.52 \\
\hline Male sex - no. (\%) & $26(60)$ & $17(40)$ & $43(51)$ & 0.07 \\
\hline Race or ethnic group - no. (\%) & & & & 0.45 \\
\hline White & $38(88)$ & $34(81)$ & $72(85)$ & \\
\hline Black & $3(7)$ & $5(12)$ & $8(9)$ & \\
\hline Asian & $2(5)$ & $1(2)$ & $3(4)$ & \\
\hline Arabic or North African & 0 & $2(5)$ & $2(2)$ & \\
\hline Weight — kg & $80.9 \pm 22.2$ & $79.7 \pm 18.3$ & $80.3 \pm 20.3$ & 0.79 \\
\hline Body-mass indext & $27.0 \pm 6.4$ & $27.8 \pm 5.8$ & $27.4 \pm 6.1$ & 0.56 \\
\hline \multicolumn{5}{|l|}{ Prednisone dose - no. (\%) } \\
\hline$\leq 30 \mathrm{mg} /$ day & $30(70)$ & $30(71)$ & $60(71)$ & 0.87 \\
\hline$>30 \mathrm{mg} /$ day & $13(30)$ & $12(29)$ & $25(29)$ & \\
\hline Treated for HES within past $5 \mathrm{yr}-$ no. (\%) & $41(95)$ & $40(95)$ & $81(95)$ & 0.98 \\
\hline \multicolumn{5}{|c|}{ Most common discontinued treatments for HES — no. (\%) } \\
\hline Any & $29(67)$ & $22(52)$ & $51(60)$ & 0.16 \\
\hline Imatinib mesylate & $18(42)$ & $14(33)$ & $32(38)$ & 0.42 \\
\hline Interferon alfa & $8(19)$ & $10(24)$ & $18(21)$ & 0.56 \\
\hline Hydroxyurea & $9(21)$ & $9(21)$ & $18(21)$ & 0.96 \\
\hline \multicolumn{5}{|c|}{ Most common ongoing treatments for HES — no. (\%) } \\
\hline Any & $34(79)$ & $36(86)$ & $70(82)$ & 0.42 \\
\hline Systemic corticosteroids & $34(79)$ & $36(86)$ & $70(82)$ & 0.42 \\
\hline Interferon alfa & $2(5)$ & $1(2)$ & $3(4)$ & 0.57 \\
\hline HES duration $-\mathrm{yr}$ & $4.3 \pm 5.6$ & $6.5 \pm 9.5$ & $5.4 \pm 7.8$ & 0.20 \\
\hline Age at HES onset $-y r$ & $42.7 \pm 17.7$ & $42.7 \pm 16.2$ & $42.7 \pm 16.9$ & 0.99 \\
\hline \multicolumn{5}{|c|}{ Most prevalent HES-related current clinical condition or disorder — no. (\%) $\mathbb{}$} \\
\hline Any & $34(79)$ & $36(86)$ & $70(82)$ & 0.42 \\
\hline Skin or subcutaneous & $16(37)$ & $24(57)$ & $40(47)$ & 0.07 \\
\hline Respiratory & $19(44)$ & $16(38)$ & $35(41)$ & 0.57 \\
\hline Nervous system & $9(21)$ & $9(21)$ & $18(21)$ & 0.96 \\
\hline Gastrointestinal & $8(19)$ & $7(17)$ & $15(18)$ & 0.81 \\
\hline Musculoskeletal & $6(14)$ & $7(17)$ & $13(15)$ & 0.73 \\
\hline Cardiac & $5(12)$ & $5(12)$ & $10(12)$ & 0.97 \\
\hline Eye & $4(9)$ & $3(7)$ & $7(8)$ & 0.72 \\
\hline \multicolumn{5}{|l|}{ Eosinophil count } \\
\hline Mean $-\times 10^{-9} /$ liter & $0.336 \pm 0.332$ & $0.561 \pm 0.921$ & $0.447 \pm 0.694$ & 0.889 \\
\hline Median $-\times 10^{-9} /$ liter & 0.210 & 0.195 & 0.200 & \\
\hline Serum interleukin-5 $-\mathrm{pg} / \mathrm{ml} \|$ & $8.7,57.0$ & 72.0 & & \\
\hline \multicolumn{5}{|l|}{ Serum tryptase $-\mu \mathrm{g} /$ liter** } \\
\hline Mean & $5.7 \pm 3.5$ & $8.2 \pm 9.8$ & $6.9 \pm 7.3$ & 0.469 \\
\hline Median & 5.0 & 6.0 & 5.0 & \\
\hline
\end{tabular}

* Plus-minus values are means \pm SD. Unless otherwise stated, $\mathrm{P}$ values were calculated with the use of a two-sided t-test with pooled variance (for continuous data) or a chi-square test (for categorical data).

$\dagger$ Race or ethnic group was assessed by the investigator at screening. "Asian" consists of East, Southeast, and South Asian.

The body-mass index is the weight in kilograms divided by the square of the height in meters.

$\int$ Patients may have had more than one current clinical condition or disorder related to the hypereosinophilic syndrome (HES).

I This $\mathrm{P}$ value was calculated with the use of the Wilcoxon rank-sum test.

$\|$ Serum interleukin-5 levels for all but three patients (two in the mepolizumab group and one in the placebo group) were under the limit of detection for the assay $(7.8 \mathrm{pg} / \mathrm{ml})$. The levels for the three individual patients are reported here.

* Serum tryptase data were available for 78 patients (41 in the mepolizumab group and 37 in the placebo group).

The New England Journal of Medicine 
Table 2. Effects of Treatment on Corticosteroid Use and Eosinophil Counts in the Intention-to-Treat Population.*

\begin{tabular}{|c|c|c|c|c|}
\hline End Point & $\begin{array}{l}\text { Mepolizumab } \\
\quad(N=43)\end{array}$ & $\begin{array}{l}\text { Placebo } \\
(\mathrm{N}=42)\end{array}$ & $\begin{array}{l}\text { Odds Ratio or Adjusted } \\
\text { Mean Difference } \\
(95 \% \mathrm{Cl}) \dot{\dagger}\end{array}$ & P Value \\
\hline \multicolumn{5}{|l|}{ Primary } \\
\hline \multicolumn{5}{|l|}{ Prednisone dose of $\leq 10 \mathrm{mg} /$ day for $\geq 8 \mathrm{wk}-$ no. (\%) } \\
\hline All patients & $36(84)$ & $18(43)$ & $8.0(2.7$ to 23.8$)$ & $<0.001$ \\
\hline Patients receiving prednisone dose of $\leq 30 \mathrm{mg} /$ day at baseline & $26 / 30(87)$ & $17 / 30(57)$ & $5.0(1.4$ to 17.8$)$ & 0.01 \\
\hline Patients receiving prednisone dose of $>30 \mathrm{mg} /$ day at baseline & $10 / 13(77)$ & $1 / 12(8)$ & 36.7 (3.3 to 412.3$)$ & $<0.001$ \\
\hline \multicolumn{5}{|l|}{ Secondary } \\
\hline \multicolumn{5}{|l|}{ Eosinophil count of $<600 / \mu \mathrm{l}$ for $\geq 8 \mathrm{wk}-$ no. (\%) } \\
\hline All patients & $41(95)$ & $19(45)$ & 18.9 (4.7 to 75.2$)$ & $<0.001$ \\
\hline Patients receiving prednisone dose of $\leq 30 \mathrm{mg} /$ day at baseline & $28 / 30(93)$ & $18 / 30(60)$ & 9.3 (1.9 to 46.7$)$ & 0.002 \\
\hline Patients receiving prednisone dose of $>30 \mathrm{mg} /$ day at baseline $\downarrow$ & $13 / 13(100)$ & $1 / 12(8)$ & & $<0.001$ \\
\hline Prednisone dose of $\leq 7.5 \mathrm{mg} /$ day for $\geq 1$ day - no. (\%) & $37(86)$ & $21(50)$ & $5.5(2.0$ to 15.0$)$ & $<0.001$ \\
\hline No prednisone for $\geq 1$ day - no. (\%) & $34(79)$ & $10(24)$ & $12.8(4.4$ to 37.4$)$ & $<0.001$ \\
\hline Prednisone dose of $\leq 10 \mathrm{mg} /$ day by wk 20 and for $\geq 8$ wk - no. (\%) & $33(77)$ & $16(38)$ & $6.0(2.2$ to 16.2$)$ & $<0.001$ \\
\hline \multicolumn{5}{|l|}{ Daily prednisone dose - mg } \\
\hline At baseline & $29.2 \pm 1.6$ & $30.6 \pm 1.9 \sqrt{\int}$ & & \\
\hline At wk 36 & $6.2 \pm 1.9$ & $21.8 \pm 1.9$ & $-15.7(-20.8$ to -10.6$)$ & $<0.001$ \\
\hline \multicolumn{5}{|l|}{ SF-12 summary scoreq } \\
\hline \multicolumn{5}{|l|}{ Physical component } \\
\hline Baseline score & $42.4 \pm 1.7$ & $42.5 \pm 1.6$ & & \\
\hline Adjusted change from baseline at wk 36 & $1.0 \pm 1.6$ & $0.4 \pm 1.7$ & $0.63(-3.73$ to 4.98$)$ & 0.78 \\
\hline \multicolumn{5}{|l|}{ Mental component } \\
\hline Baseline score & $48.3 \pm 1.8$ & $43.4 \pm 1.5$ & & \\
\hline Adjusted change from baseline at wk 36 & $2.4 \pm 1.6$ & $0.2 \pm 1.7$ & $2.20(-2.24$ to 6.64$)$ & 0.33 \\
\hline \multicolumn{5}{|l|}{ Exploratory } \\
\hline Prednisone dose of $\leq 10 \mathrm{mg} /$ day for $\geq 24 \mathrm{wk}-$ no. (\%) & $24(56)$ & $6(14)$ & $7.8(2.7$ to 23.0$)$ & $<0.001$ \\
\hline No prednisone during treatment period and untiil study completion - no. (\%) & $20(47)$ & $2(5)$ & 17.7 (3.7 to 83.8$)$ & $<0.001$ \\
\hline
\end{tabular}

* Plus-minus values are means \pm SE. Odds ratios and hazard ratios were adjusted for prednisone dose at baseline $(\leq 30 \mathrm{mg}$ per day vs. $>30$ $\mathrm{mg}$ per day). Hazard ratios are not reported for end points for which the assumption of proportional hazards was not fulfilled.

$\uparrow$ The odds ratio is given for categorical variables. For the continuous variables SF-12 scores and daily dose, the adjusted mean difference was calculated, with the use of analysis of variance, and the adjusted change from baseline at week 36 was calculated with the use of last-observation-carried-forward analysis.

$\checkmark$ The odds ratio for this subgroup could not be calculated because of the $100 \%$ incidence in the mepolizumab group.

$\int$ This value is based on data from 41 patients only, since 1 patient received only one infusion.

9 The SF-12 (version 2) physical and mental component summary scores were transformed to a mean of 50 and an SD of 10 in the general U.S. population. ${ }^{25}$ Higher scores indicate a better state of health and better functioning. Scores were known for 38 patients in the mepolizumab group and 35 in the placebo group.

\section{RESULTS}

BASELINE CHARACTERISTICS

Of the 107 patients screened, 85 were randomly assigned to treatment with mepolizumab (43 patients) or placebo (42 patients). The majority of patients in the mepolizumab group (36 of 43 [84\%]) completed the trial, as compared with only 15 of $42(36 \%)$ in the placebo group (Fig. 1B). The most common reason for withdrawal was lack of efficacy (5 of 43 patients [12\%] receiving mepolizum$\mathrm{ab}$ and 21 of $42[50 \%]$ receiving placebo).

There were no significant differences in demographic or disease characteristics between the 


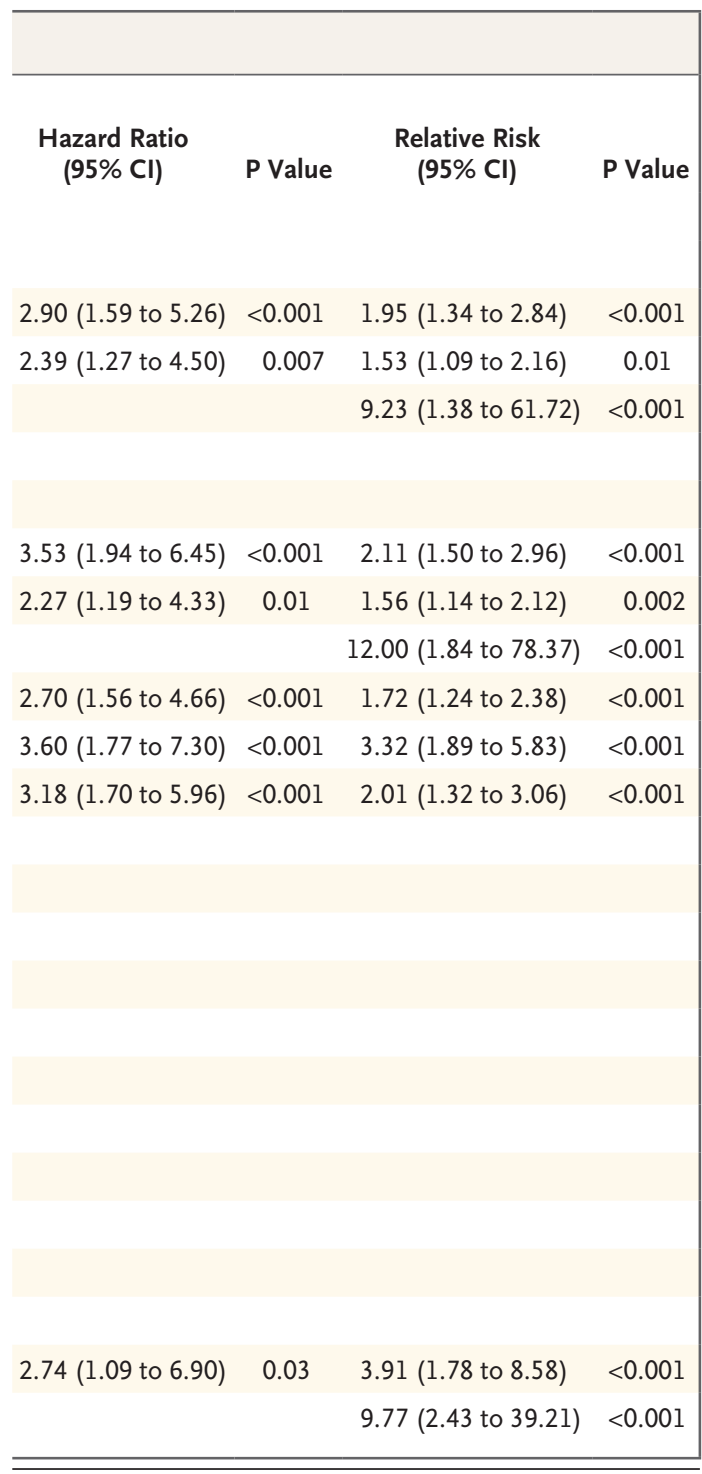

study groups at the time of randomization (Table 1). Of note, the mean duration of disease was more than 5 years, and the majority of patients (82\%) reported at least one clinical manifestation of the hypereosinophilic syndrome.

\section{EFFICACY}

Prednisone-Sparing Effects

Overall, for 36 patients (84\%) receiving mepolizumab and 18 (43\%) receiving placebo, the prednisone dose was reduced to $\leq 10 \mathrm{mg}$ per day for $\geq 8$ consecutive weeks during the 36 -week treatment period (primary end point) (hazard ratio, 2.90; 95\% confidence interval [CI], 1.59 to 5.26; $\mathrm{P}<0.001$ ) (Table 2 and Fig. 2A). Similar results were obtained when the primary end point was analyzed for the modified per-protocol population of 78 patients (hazard ratio, 3.27; 95\% CI, 1.73 to 6.18; $\mathrm{P}<0.001)$. A significant difference between the two study groups was also found for the subgroups of prednisone dose at baseline, being more pronounced among patients requiring more than $30 \mathrm{mg}$ per day than among those requiring $30 \mathrm{mg}$ or less per day (Table 2). In the placebo group, the primary end point was more likely to be reached among patients who had been receiving $30 \mathrm{mg}$ or less of prednisone at baseline (17 of 30 patients [57\%]) than among those who had been receiving more than $30 \mathrm{mg}$ ( 1 of 12 [8\%]). In contrast, in the mepolizumab group, 26 of the 30 patients (87\%) who had been receiving $30 \mathrm{mg}$ or less of prednisone at baseline were responders, as were 10 of 13 (77\%) who had been receiving more than $30 \mathrm{mg}$.

All secondary and exploratory efficacy end points significantly favored the use of mepolizumab ( $\mathrm{P}<0.001)$ (Table 2 and Fig. 2B). Figure 2D shows the mean prednisone dose used during the study. (Additional efficacy analyses, with stratification on the basis of achievement of the primary end point and status of study completion, are presented in Supplementary Appendix 3.)

\section{Blood Eosinophil Counts and Eosinophil-Derived Neurotoxin Levels}

A blood eosinophil count of less than 600 per microliter for 8 or more consecutive weeks was reached in 41 of the 43 patients $(95 \%)$ receiving mepolizumab, as compared with 19 of the 42 (45\%) receiving placebo $(\mathrm{P}<0.001$; hazard ratio, 3.53; $95 \%$ CI, 1.94 to 6.45) (Table 2 and Fig. 2C). The difference between the study groups for this end point was significant in both subgroups of baseline prednisone dose ( $\leq 30 \mathrm{mg}$ and $>30 \mathrm{mg}$ ). Mean serum eosinophil-derived neurotoxin levels were significantly different between the two study groups at all time points evaluated $(\mathrm{P}<0.001, \mathrm{P}<0.001$, and $\mathrm{P}=0.005$ for reductions between the mepolizumab group and the placebo group at weeks 12, 24, and 36, respectively) (Fig. 2F).

\section{Time to Treatment Failure}

The time to treatment failure (defined as the number of days to clinical worsening requiring other therapy for the hypereosinophilic syndrome or an increase in the prednisone dose to $>60 \mathrm{mg}$ per day) was significantly shorter in the placebo group than in the mepolizumab group $(\mathrm{P}<0.001$ by the log-rank test). Nine of 43 patients (21\%) receiving 
mepolizumab and 29 of 42 (69\%) receiving placebo had treatment failure. The median time to treatment failure in the placebo group was 136.5 days (95\% CI, 106 to 199; Fig. 2E); corresponding data could not be calculated for mepolizumab, since less than half the patients receiving that drug had treatment failure.

\section{Health Outcomes}

No significant differences between treatments were observed in the changes from baseline in SF-12 physical and mental component summary scores (Table 2) or the Rotterdam Symptom Checklist (Supplementary Appendix 3).

\section{SAFETY}

The mean $( \pm S D)$ duration of exposure to study drug (defined as the time between the first and last infusions) was greater in the mepolizumab group (6.7 \pm 1.9 months) than in the placebo group (4.3 \pm 2.6 months) because of a lower withdrawal rate. Despite the longer exposure to mepolizumab, adverse events were reported at similar rates in the two study groups: 40 of 43 patients (93\%) receiving mepolizumab and 41 of $42(98 \%)$ receiving placebo (Table 3). An adverse event considered by the investigator to be related to the study drug occurred in 16 of 43 patients (37\%) in the mepolizumab group and in 12 of 42 (29\%) in the placebo group (Table 3). One patient receiving mepolizum$\mathrm{ab}$ and four receiving placebo had adverse events leading to withdrawal; none of these events were considered by the investigator to be related to study drug. No clinically relevant trends or major safety concerns emerged from evaluation of the laboratory tests, vital signs, or electrocardiographic results.

Serious adverse events occurred in seven patients receiving mepolizumab (14 events, including one death) and five patients receiving placebo (7 events) (Table 3), but none were deemed by the investigator to be related to the study drug. Serious adverse events in the mepolizumab group were asthma, clinical flares of the hypereosinophilic syndrome, pneumonia, renal failure, bronchitis, cardiac arrest, dehydration, hepatitis, pancreatitis, pyrexia, rhinitis, and spinal compression fracture. Serious adverse events in the placebo group were clinical flares of the hypereosinophilic syndrome, pneumonia, dysesthesia, eosinophilia, nephrotic
Figure 2 (facing page). Efficacy of Mepolizumab Treatment.

Panel A shows the percentage of patients in whom the prednisone dose was reduced to $10 \mathrm{mg}$ or less per day (or the equivalent) for 8 or more consecutive weeks (the primary end point). Panel B shows the percentage of patients in whom the prednisone dose was reduced to $10 \mathrm{mg}$ or less per day for 24 or more consecutive weeks. Panel $\mathrm{C}$ shows the percentage of patients in whom the blood eosinophil count was maintained at or below 600 per microliter for 8 or more consecutive weeks. Panel D shows the mean prednisone (or the equivalent) daily dose during the study. The lastobservation-carried-forward (LOCF) data are those from the second infusion onward. Panel $E$ is a KaplanMeier plot of the time to treatment failure (defined as clinical worsening requiring other therapy for the hypereosinophilic syndrome, a prednisone dose of $>60 \mathrm{mg}$ per day, or study withdrawal for any reason) in the intention-to-treat population. Panel F shows the mean serum eosinophil-derived neurotoxin (EDN) values. The I bars in Panels D and F indicate standard errors.

syndrome, osteonecrosis, and polyneuropathy. An 18-year-old man with severe hypereosinophilic syndrome and a history of multiple cardiovascular coexisting conditions died 110 days after his first mepolizumab infusion, and 26 days after his fourth and last infusion, from a cardiac arrest attributed to dysrhythmia and internal pacemakerdefibrillator failure. (Supplementary Appendixes 2 and 4 contain additional information about adverse events.)

\section{DISCUSSION}

The hypereosinophilic syndrome is a potentially severe and debilitating multisystem disorder associated with considerable morbidity, in part due to the side effects of treatments currently used for it. We report evidence that corticosteroid-sparing is enabled by mepolizumab in patients negative for FIP1L1-PDGFRA with the hypereosinophilic syndrome. Treatment with prednisone, which could be discontinued until study completion, was able to be stopped during the study in almost $50 \%$ of patients receiving mepolizumab.

Mepolizumab also was significantly more effective than placebo at stabilizing blood eosinophil counts. These effects are clinically relevant, given that reducing eosinophil levels is currently the primary treatment goal for patients with the hypereosinophilic syndrome and that long-term 


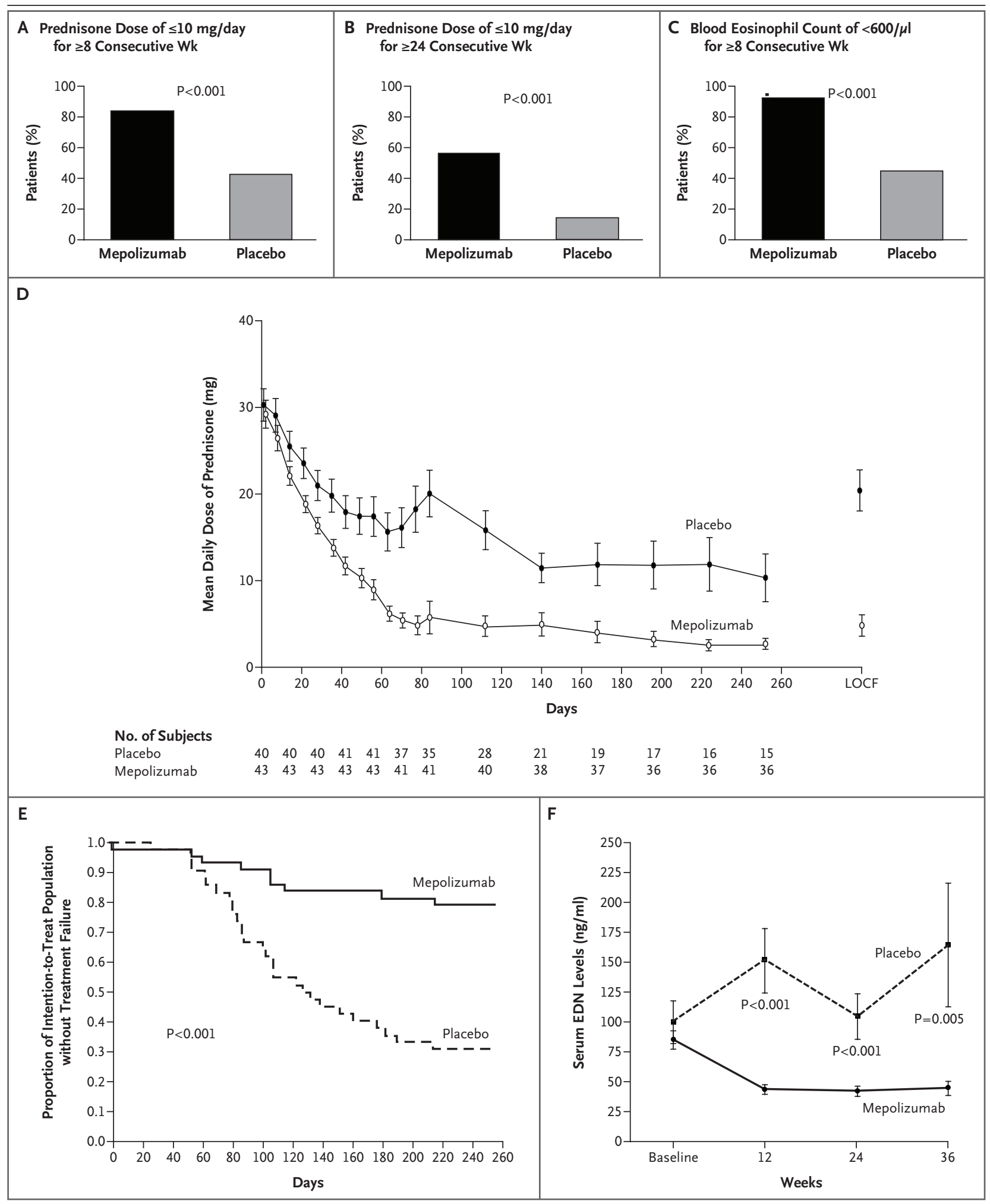

N ENGLJ MED 358;12 WWW.NEJM.ORG MARCH 20, 2008

The New England Journal of Medicine 
Table 3. Adverse Events Reported during the 36-Week Study.*

Event

Mepolizumab $(\mathrm{N}=43) \quad$ Placebo $(\mathrm{N}=42)$

number of patients (percent)

\section{Serious adverse event}

Any

Asthma

Hypereosinophilic syndrome flare

Pneumonia

Renal failure

Bronchitis

Cardiac arrest

Dehydration

Dysesthesia

Eosinophilia

Hepatitis

Nephrotic syndrome

Osteonecrosis

Pancreatitis

Polyneuropathy

Pyrexia

Rhinitis resulting in hospital admission

Spinal compression fracture

Adverse event

Any event

Fatigue

Pruritus

Headache

Arthralgia

Nausea

Diarrhea

Cough

Dyspnea

Upper respiratory tract infection

Back pain

Myalgia

Peripheral edema

Sinusitis

Rash

Abdominal pain

Pyrexia

Vomiting

Asthma

Dizziness
7 (16)

2 (5)

1 (2)

1 (2)

2 (5)

1 (2)

1 (2)

1 (2)

0

0

1 (2)

0

0

$1(2)$

0

1 (2)

1 (2)

1 (2)

40 (93)

$13(30)$

12 (28)

$10(23)$

9 (21)

8 (19)

8 (19)

5 (12)

7 (16)

9 (21)

5 (12)

8 (19)

7 (16)

5 (12)

4 (9)

4 (9)

3 (7)

5 (12)

5 (12)

5 (12)
5 (12)

0

1 (2)

1 (2)

0

0

0

0

1 (2)

1 (2)

0

$1(2)$

1 (2)

0

1 (2)

0

0

0

41 (98)

$11(26)$

9 (21)

9 (21)

7 (17)

7 (17)

6 (14)

8 (19)

6 (14)

4 (10)

$6(14)$

3 (7)

4 (10)

6 (14)

6 (14)

5 (12)

6 (14)

4 (10)

$3(7)$

3 (7)

The New England Journal of Medicine

Downloaded from nejm.org on May 1, 2016. For personal use only. No other uses without permission. Copyright (c) 2008 Massachusetts Medical Society. All rights reserved. 


\begin{tabular}{|c|c|c|}
\hline \multirow[t]{2}{*}{ Event } & Mepolizumab $(\mathrm{N}=43)$ & Placebo $(\mathrm{N}=42)$ \\
\hline & \multicolumn{2}{|c|}{ number of patients (percent) } \\
\hline Nasopharyngitis & $4(9)$ & $4(10)$ \\
\hline Rhinitis & $6(14)$ & $2(5)$ \\
\hline Pharyngolaryngeal pain†† & $1(2)$ & $6(14)$ \\
\hline Bronchitis & $5(12)$ & $1(2)$ \\
\hline Chest pain & $4(9)$ & $2(5)$ \\
\hline Clinically significant or unexpected worsening of HES & $2(5)$ & $4(10)$ \\
\hline Pain in extremity & $1(2)$ & $5(12)$ \\
\hline Paresthesia & $3(7)$ & $3(7)$ \\
\hline Urticaria & $5(12)$ & $1(2)$ \\
\hline Acne & $3(7)$ & $2(5)$ \\
\hline Contusion & $2(5)$ & $3(7)$ \\
\hline Erythema & $3(7)$ & $2(5)$ \\
\hline Muscle spasms & $3(7)$ & $2(5)$ \\
\hline Facial swelling & $2(5)$ & $3(7)$ \\
\hline Neck pain & $1(2)$ & $3(7)$ \\
\hline Papular rash & $1(2)$ & $3(7)$ \\
\hline Allergic rhinitis & $4(9)$ & 0 \\
\hline Urinary tract infection & $1(2)$ & $3(7)$ \\
\hline Alopecia & $3(7)$ & 0 \\
\hline Epistaxis & $3(7)$ & 0 \\
\hline Productive cough & $3(7)$ & 0 \\
\hline \multicolumn{3}{|l|}{ Drug-related adverse event } \\
\hline Any event & $16(37)$ & $12(29)$ \\
\hline Headache & $2(5)$ & $4(10)$ \\
\hline Arthralgia & $4(9)$ & $2(5)$ \\
\hline Fatigue & $4(9)$ & $1(2)$ \\
\hline Peripheral edema & 0 & $4(10)$ \\
\hline Pruritus & $2(5)$ & $2(5)$ \\
\hline Myalgia & $2(5)$ & $2(5)$ \\
\hline Erythema & $1(2)$ & $2(5)$ \\
\hline Rash & $1(2)$ & $2(5)$ \\
\hline Increased $\gamma$-glutamyltransferase & $2(5)$ & 0 \\
\hline Cough & 0 & $3(7)$ \\
\hline Dyspnea & 0 & $2(5)$ \\
\hline
\end{tabular}

* Some patients had more than one adverse event. The serious adverse events and adverse events listed were those reported at an incidence of more than $5 \%$ per study group. The drug-related adverse events listed (those considered to be such by the investigator) were those reported at an incidence of more than $4 \%$ per study group. No statistical testing was performed on data for drug-related adverse events. For serious adverse events and adverse events, all comparisons were not significant, unless otherwise noted. HES denotes the hypereosinophilic syndrome.

$\dagger \mathrm{P}=0.03$ for the comparison of the mepolizumab group and the placebo group.

$\mathrm{P}=0.047$ for the comparison of the mepolizumab group and the placebo group.

The New England Journal of Medicine 
corticosteroid therapy is associated with a range of undesirable side effects. ${ }^{26-28}$ Since the corticosteroid threshold associated with clinically significant toxic effects has been established at approximately $7.5 \mathrm{mg}$ per day of prednisone equivalent, ${ }^{27}$ it is notable that a prednisone dose of $7.5 \mathrm{mg}$ or less per day in this study was achieved in significantly more patients receiving mepolizumab than in those receiving placebo.

No significant differences were found between the two study groups in SF-12 (version 2) assessments, which may reflect the protocol requirements for disease to be clinically stable at baseline and for stability to be maintained in order for the patient to remain in the trial. As such, the quality of life, as measured by the SF-12 survey, did not deteriorate during the study period. In addition, the baseline mental-component summary score in the mepolizumab group was similar to that for the general U.S. population, ${ }^{25}$ indicating that with treatment, patients did not feel impaired by their disease, making it difficult to show an improvement. The study population was composed of relatively young patients who were negative for FIP1L1-PDGFRA and had long-standing corticosteroid-responsive hypereosinophilic syndrome. The corticosteroid-sparing effects observed in our study suggest that mepolizumab has substantial potential to reduce treatment-related morbidity. Because this study was limited to patients who were receiving corticosteroid therapy and whose hypereosinophilic syndrome was clinically well controlled, no recommendations can be inferred regarding the use of mepolizumab for patients with acute presentations or who have not yet received corticosteroid therapy. The same holds true for patients with the hypereosinophilic syndrome that is unresponsive to systemic corticosteroids, as well as those positive for FIP1L1-PDGFRA. ${ }^{29}$

Mean serum interleukin-5 values at baseline were below the limit of detection (7.8 pg per milliliter) in most patients (Table 1). Such normal serum interleukin-5 levels are probably due to corticosteroid-induced suppression, since patients' symptoms were stabilized by means of corticosteroid therapy before randomization. The efficacy of mepolizumab in patients with physiologic levels of interleukin- 5 suggests that this agent should not be reserved for patients with elevated serum interleukin-5 levels. Our results provide evidence that endogenous interleukin-5 in these patients with the hypereosinophilic syndrome has a critical role in regulating peripheral eosinophilia.

Our study assessed the effects of mepolizumab administered monthly during a 36-week treatment period, whereas previous studies of mepolizumab evaluated 12 weeks of treatment. 15,17,18,22,30 Several of these studies focused on the treatment of asthma, showing significant reductions in blood, sputum, and bronchial eosinophil counts and safety but limited efficacy as measured by pulmonary-function testing. ${ }^{15-18}$ Much remains to be learned about the relation between blood and tissue eosinophilia and clinical response to treatment in patients with asthma and the hypereosinophilic syndrome. Although the number of patients in our trial was small, the preliminary findings suggest that the likelihood of achieving the primary end point with the use of mepolizumab was high in the patients with current conditions related to the hypereosinophilic syndrome. The primary end point was reached in 17 of the 19 patients with respiratory disorders, 5 of the 5 with cardiac disorders, 8 of the 8 with gastrointestinal disorders, 5 of the 6 with musculoskeletal disorders, and 8 of the 9 with nervoussystem disorders, although in only 11 of the 16 patients with skin or subcutaneous manifestations (Table 1, and Supplementary Appendix 5).

In theory, since interleukin-5 potently primes eosinophils for enhanced responsiveness to activating signals, ${ }^{6}$ anti-interleukin- 5 may be particularly helpful for reducing the eosinophil-mediated end-organ pathologic characteristics typically associated with the hypereosinophilic syndrome. Tissue and vascular damage results in part from the release of granule proteins, and mepolizumab treatment was associated with significant reductions in eosinophil-derived neurotoxin levels in our study (Fig. 2F). In addition, the chronic tissue damage associated with the hypereosinophilic syndrome is thought to be mediated by eosinophil infiltration, and mepolizumab probably decreases tissue eosinophil levels in patients with the syndrome. ${ }^{21,22}$

Adverse effects were found in the mepolizumab group. One patient receiving mepolizumab had a fatal cardiac arrest, which was not considered to be drug-related by the investigator, who was unaware of the group assignment. Adverse events considered drug-related by the investigator were similar between the mepolizumab group and the 
placebo group. This finding is noteworthy, since the duration of exposure to study drug was approximately $56 \%$ longer for mepolizumab than for placebo, owing to the greater dropout rate (because of lack of efficacy) in the placebo group. In addition, some adverse events in both groups may have resulted from prednisone withdrawal rather than use of the study drug.

An ongoing, open-label extension trial, involving 78 patients from the current trial, will provide long-term information on potential safety issues, efficacy assessments, and optimal dosing frequency (see Supplementary Appendix 4 for details). This trial will help address whether long-term treatment with mepolizumab will durably reduce eosinophil counts while controlling disease.

In conclusion, our study demonstrated that mepolizumab treatment enabled clinically significant reductions in corticosteroid dose, and often corticosteroid discontinuation, in patients negative for FIP1L1-PDGFRA who had the hypereosinophilic syndrome. This proof-of-concept study shows that administration of anti-interleukin-5 antibodies, an eosinophil-specific and targeted therapy, has a potential clinical benefit.

Supported by grants from GlaxoSmithKline, the National Institutes of Health (M01 RR00064 and AI61097, to Dr. Gleich, and MO1 RR001032, to the Beth Israel Deaconess Medical Cen- ter), U.S. Public Health Service General Clinical Research Center (M01 RR 08084, to the Cincinnati Children's Medical Center), and the Intramural Research Program of the National Institute of Allergy and Infectious Diseases.

Dr. Rothenberg reports receiving lecture fees from Merck and consulting fees from GlaxoSmithKline, Ception Therapeutics, Merck, and Cambridge Antibody Technology and having equity interests in Ception Therapeutics. Drs. Roufosse and Kahn report receiving consulting fees from GlaxoSmithKline. Dr. Weller reports receiving consulting fees from GlaxoSmithKline, Medimmune, Genzyme, and Microbia. Dr. Simon reports receiving consulting fees from GlaxoSmithKline, Pfizer, and Novartis and grant support from GlaxoSmithKline. Dr. Schwartz reports receiving consulting fees from GlaxoSmithKline, Genentech, and Novartis; royalties from Phadia through Virginia Commonwealth University for tryptase immunoassay licensing rights; and grant support from GlaxoSmithKline, the Philip Morris Foundation, and Pharming. Dr. Rosenwasser reports receiving consulting fees from Abbott Laboratories, Alcon Laboratories, Regeneron, GlaxoSmithKline, Novartis, AstraZeneca, and Genentech and lecture fees from Alcon Laboratories, Genentech, and Novartis. Dr. Ring reports receiving consulting fees from Astellas, Novartis, GlaxoSmithKline, and Schering-Plough. Dr. Griffin reports having been an employee of GlaxoSmithKline. Ms. Haig, Mr. Frewer, and Dr. Parkin report having equity interests in and being employees of GlaxoSmithKline. Dr. Gleich reports receiving consulting fees from GlaxoSmithKline, Genentech, and Novartis; lecture fees from Novartis, Genentech, and Sepracor; royalties from the Mayo Clinic for discoveries and patents; grant support from Jerini, Novartis, and GlaxoSmithKline; and having equity interests in Ception. No other potential conflict of interest relevant to this article was reported.

We thank the members of the medical, nursing, and research staff at the trial centers for their invaluable contributions to this study, as well as Ellen Lewis, Ph.D., for assistance with preparation of a previous version of the manuscript.

\section{APPENDIX}

In addition to the authors, the members of the Mepolizumab HES Study Group are as follows: Australia: Sir Charles Gairdner Hospital, Perth — A. Singh, D. Joske; Royal North Shore Hospital, Sydney — L. Coyle; Mater Adult Hospital, Brisbane — K. Taylor; Royal Melbourne Hospital, Melbourne - J. Szer; Belgium: University Hospital Gasthuisberg, Leuven - D. Blockmans, G. Verhoef; Canada: Royal Victoria Hospital, Montreal — W. Carey; McMaster University, Hamilton, ON — J. Denburg; Cancer Care Nova Scotia, Halifax, NS - A. Padmos; University of Toronto, Toronto - N. Shear; Winnipeg Clinic, Winnipeg, MB - V. Taraska; France: Hôpital Foch, Suresnes - O. Blétry; Claude-Huriez Hospital, Lille — P.-Y. Hatron; Germany: Hannover Medical School, Hannover — A. Ganser; Rheumaklinik Bad Bramstedt and Universitätsklinikum Schleswig-Holstein, Bad Bramstedt - W. Gross; Italy: L. and A. Seràgnoli, University of Bologna, Bologna - M. Baccarani; Switzerland: Dermatologische Universitätsklinik und Poliklinik, Inselspital Bern, Bern — L.R. Braathen; United States: Cincinnati Children's Hospital Medical Center, Cincinnati — A. Assa'ad; University of Wisconsin School of Medicine, Madison — W. Busse; Mayo Clinic, Rochester, MN — J. Butterfield; University of Utah Health Sciences Center, Salt Lake City - K. Leiferman; Vanderbilt University Medical Center, Nashville - J. Murray, D. Hagaman; University ofCalifornia San Diego School of Medicine, San Diego — J. Ramsdell; Beth Israel Deaconess Medical Center, Boston — J. Sheikh; National Institutes of Health, Bethesda, MD — C.A. Talar-Williams; University of Texas M.D. Anderson Cancer Center, Houston — S. Verstovsek; National Jewish Medical and Research Center, Denver — R. Weber.

REFERENCES

1. Klion AD, Bochner BS, Gleich GJ, et al. Approaches to the treatment of hypereosinophilic syndromes: a workshop summary report. J Allergy Clin Immunol 2006; 117:1292-302.

2. Gleich GJ, Leiferman KM. The hypereosinophilic syndromes: still more heterogeneity. Curr Opin Immunol 2005;17:67984.

3. Roufosse F, Goldman M, Cogan E. Hypereosinophilic syndrome: lymphoproliferative and myeloproliferative variants. Semin Respir Crit Care Med 2006;27:158-70.

4. Wilkins HJ, Crane MM, Copeland K,
Williams WV. Hypereosinophilic syndrome: an update. Am J Hematol 2005;80: 148-57.

5. Kariyawasam HH, Robinson DS. The eosinophil: the cell and its weapons, the cytokines, its locations. Semin Respir Crit Care Med 2006;27:117-27.

6. Rothenberg ME, Hogan SP. The eosinophil. Annu Rev Immunol 2006;24:147-74. 7. Lopez AF, Sanderson CJ, Gamble JR, Campbell HD, Young IG, Vadas MA. Recombinant human interleukin 5 is a selective activator of human eosinophil function. J Exp Med 1988;167:219-24.
8. Clutterbuck EJ, Hirst EM, Sanderson CJ. Human interleukin-5 (IL-5) regulates the production of eosinophils in human bone marrow cultures: comparison and interaction with IL-1, IL-3, IL-6, and GMCSF. Blood 1989;73:1504-12.

9. Sanderson CJ. Interleukin-5, eosinophils, and disease. Blood 1992;79:3101-9. 10. Simon D, Braathen LR, Simon H-U. Eosinophils and atopic dermatitis. Allergy 2004;59:561-70.

11. Sutton SA, Assa'ad AH, Rothenberg ME. Anti-IL-5 and hypereosinophilic syndromes. Clin Immunol 2005;115:51-60. 
12. Schrezenmeier H, Thomé SD, Tewald F, Fleischer B, Raghavachar A. Interleukin-5 is the predominant eosinophilopoietin produced by cloned T lymphocytes in hypereosinophilic syndrome. Exp Hematol 1993;21:358-65.

13. Cook R, Applebaum R, Cusimano D, et al. Biological and biophysical characteristics of SB 240563, a high affinity humanized monoclonal antibody to IL-5. Am J Crit Care Med 1998;157:A604. abstract.

14. Hart TK, Cook RM, Zia-Amirhosseini $\mathrm{P}$, et al. Preclinical efficacy and safety of mepolizumab (SB-240563), a humanized monoclonal antibody to IL-5, in cynomolgus monkeys. J Allergy Clin Immunol 2001;108:250-7.

15. Büttner C, Lun A, Splettstoesser T, Kunkel G, Renz H. Monoclonal anti-interleukin-5 treatment suppresses eosinophil but not T-cell functions. Eur Respir J 2003; 21:799-803.

16. Leckie MJ, ten Brinke A, Khan J, et al. Effects of an interleukin-5 blocking monoclonal antibody on eosinophils, airway hyper-responsiveness, and the late asthmatic response. Lancet 2000;356:2144-8. 17. Flood-Page PT, Menzies-Gow AN, Kay $\mathrm{AB}$, Robinson DS. Eosinophil's role remains uncertain as anti-interleukin-5 only partially depletes numbers in asthmatic airway. Am J Respir Crit Care Med 2003;167:199-204.

18. Menzies-Gow A, Flood-Page P, Sehmi
$\mathrm{R}$, et al. Anti-IL-5 (mepolizumab) therapy induces bone marrow eosinophil maturational arrest and decreases eosinophil progenitors in the bronchial mucosa of atopic asthmatics. J Allergy Clin Immuno 2003;111:714-9.

19. Oldhoff JM, Darsow U, Werfel T, et al. Anti-IL-5 recombinant humanized monoclonal antibody (mepolizumab) for the treatment of atopic dermatitis. Allergy 2005;60:693-6.

20. Koury MJ, Newman JH, Murray JJ. Reversal of hypereosinophilic syndrome and lymphomatoid papulosis with mepolizumab and imatinib. Am J Med 2003;115 587-9.

21. Plötz SG, Simon H-U, Darsow U, et al Use of an anti-interleukin-5 antibody in the hypereosinophilic syndrome with eosinophilic dermatitis. N Engl J Med 2003; 349:2334-9.

22. Garrett JK, Jameson SC, Thomson B et al. Anti-interleukin-5 (mepolizumab) therapy for hypereosinophilic syndromes. J Allergy Clin Immunol 2004;113:115-9.

23. Chusid MJ, Dale DC, West BC, Wolff SM. The hypereosinophilic syndrome: analysis of fourteen cases with review of the literature. Medicine (Baltimore) 1975; 54:1-27.

24. Pardanani A, Ketterling RP, Brockman SR, et al. CHIC2 deletion, a surrogate for FIP1L1-PDGFRA fusion, occurs in systemic mastocytosis associated with eo- sinophilia and predicts response to imatinib mesylate therapy. Blood 2003;102: 3093-6.

25. Ware JE, Kosinski M, Keller SD. SF-12: how to score the SF-12 Physical and Mental Health Summary Scales. Boston: The Health Institute, New England Medical Center, 1995.

26. Stanbury RM, Graham EM. Systemic corticosteroid therapy - side effects and their management. Br J Ophthalmol 1998; 82:704-8.

27. Wei L, MacDonald TM, Walker BR. Taking glucocorticoids by prescription is associated with subsequent cardiovascular disease. Ann Intern Med 2004;141:764-70.

28. Rhen T, Cidlowski JA. Antiinflammatory action of glucocorticoids - new mechanisms for old drugs. N Engl J Med 2005;353:1711-23

29. Klion AD, Law MA, Noel P, Kim YJ, Haverty TP, Nutman TB. Safety and efficacy of the monoclonal anti-interleukin-5 antibody SCH55700 in the treatment of patients with hypereosinophilic syndrome. Blood 2004;103:2939-41.

30. Phipps S, Flood-Page P, Menzies-Gow A, Ong YE, Kay AB. Intravenous anti-IL-5 monoclonal antibody reduces eosinophils and tenascin deposition in allergen-challenged human atopic skin. J Invest Dermatol 2004;122:1406-12.

Copyright (C) 2008 Massachusetts Medical Society. Internet, with selected slides from the presentation, will not be considered prior publication. This will allow students and physicians who are unable to attend the meeting to hear the presentation and view the slides. If there are any questions about this policy, authors should feel free to call the Journal's Editorial Offices. 